\title{
Evaluation of antioxidant capacity of the aqueous extract of Cynara scolymus L. (Asteraceae) in vitro and in Saccharomyces cerevisiae
}

\author{
George Laylson da Silva Oliveira ${ }^{1}$, Francisco Rodrigo de Asevedo Mendes de Oliveira', \\ Marcus Vinícius Oliveira Barros de Alencar ${ }^{1}$, Antonio Luiz Gomes Junior ${ }^{1}$, Alexandre Araujo \\ de Souza $^{2}$, Ana Amélia de Carvalho Melo Cavalcante ${ }^{1}$ and Rivelilson Mendes de Freitas ${ }^{1 *}$ \\ ${ }^{1}$ Post-Graduation Program in Pharmaceutics Science, Federal University of Piaui, Teresina, PI, 64048-901, Brazil. \\ ${ }^{2}$ Federal University of Piauí, CCN, Chemistry Department, Ininga, Teresina, PI, 64048-901, Brazil.
}

Accepted 3 February, 2014

\begin{abstract}
The present study evaluated the antioxidant capacity of the aqueous extract of the leaves of Cynara scolymus on Saccharomyces cerevisiae strains, proficient and deficient in antioxidant defenses, and by in vitro methods with 1,1-diphenyl-2-picrylhydrazyl (DPPH•), 2,2'-azinobis-3-ethylbenzothiazoline-6sulfonic acid (ABTS $\cdot^{+}$), inhibition of hydrogen peroxide, lipid peroxidation, formation of nitric oxide, and removal of the hydroxyl radical. A simultaneous quantitative analysis to total phenolics, flavonoids and hydrolysable tannin was also performed, and according to the results obtained, phenolic compounds (661.15 $\pm 20.11 \mathrm{mg} \mathrm{GAE} / \mathrm{g}$ of E), flavonoids (123.96 $\pm 11.47 \mathrm{mg} \mathrm{R} / \mathrm{g}$ of E) and hydrolysable tannin (14.25 \pm $3.18 \mathrm{mg} \mathrm{GAE} / \mathrm{g}$ of E) were detected in the aqueous extract of $C$. scolymus. The aqueous extract at study showed high antioxidant capacity in all antioxidant methods in vitro and exhibited significant antioxidant capacity to protect strains of $S$. cerevisiae from oxidative damage induced by hydrogen peroxide. The analysis of the correlation made between the content of phenolic compounds and the different antioxidants in vitro methods, indicated that these compounds are mainly responsible for the antioxidant capacity of the aqueous extract of $C$. scolymus. Therefore, this study suggests that the aqueous extract of leaves of $C$. scolymus is a great natural source of compounds with antioxidant capacity.
\end{abstract}

Key words: Antioxidant capacity, Cynara scolymus, Saccharomyces cerevisiae, phenolic compounds.

\section{INTRODUCTION}

Reactive oxygen (ROS) and nitrogen (RNS) species, as well as other free radicals are potentially capable of producing damage in various biological macromolecules (DNA, proteins and lipids) playing an important role in the etiology of various diseases such as cancer, diabetes, cardiovascular diseases and premature aging (Kryston et al., 2011; Bhattacharya et al., 2011; Liochev, 2013). Some enzymatic antioxidant mechanisms promote the protection of human cells against the harmful effects of free radicals, but these antioxidant mechanisms may not be enough to combat oxidative stress, which results from the imbalance between production and elimination of free radicals (Jensen, 2003). Accordingly, certain amounts of antioxidant supplements are necessary to ensure the balance of reactive species derived from oxygen and nitrogen produced by pathophysiological metabol 
(Dizdaroglu et al., 2002; Sailaja Rao et al., 2011).

Over the last decade, interest in the search for antioxidants from natural sources has increased and various studies by the scientific community have reported the importance of fruits and vegetables in the prevention of chronic diseases resulting from oxidative stress (Gulcin, 2012). The plants have a rich source of molecules with antioxidant potential, as phenolic compounds, carotenoids, vitamins, flavonoids and terpenoids (Kumar et al., 2012; Ranilla et al., 2010). Therefore, greater attention is turned to the antioxidants of natural origin, which may act by inhibiting lipid peroxidation and/or neutralizing reactive oxygen species and nitrogen, resulting in the modulation of oxidative stress (Fadel et al., 2011).

Cynara scolymus L. (Asteraceae) is a native plant of the Mediterranean (North Africa and southern Europe) and popularly known in Brazil as artichoke. Regardless of its origin in regions of subtropical climates, the $C$. scolymus is cultivated worldwide because of its nutritional benefits and medicinal properties (Lattanzio et al., 2009). Since ancient times, the $C$. scolymus has been cited as a drug in traditional medicine and in much of the world it is attached to beneficial effects in diseases of the biliary tract, digestive action, and help in the treatment of scurvy, anemia and antiesclerotic effect (Gebhardt, 1997; Kraft, 1997; Kucukgergin et al., 2010). The C. scolymus is a plant used for medicinal purposes and is considered a healthy food because of its nutritional composition and phytochemistry, which contain minerals, proteins, phenolic derivatives including caffeoylquinic acid (chlorogenic acid and 1.5 dicaffeoylquinic cinarina), tannins, flavonoids and sesquiterpenes in fewer quantities, and various aliphatic acids, especially hydroxy acids (lactic, malic, glycolic) (Pandino et al., 2011; Bundy et al., 2008). Several pharmacological and preclinical stu-dies using the aqueous extract of leaves of $C$. scolymus demonstrated antibacterial, anti-HIV, hepato-protective, hepatostimulant, hypocholesterolemic, choleretic, diuretic and antioxidant effects (Joy and Haber, 2007; Miccadei et al., 2008; Lutz et al., 2011; Qiang et al., 2012).

The interest in working with medicinal plants is the therapeutic value they have and because there are few studies on the antioxidant capacity of $C$. scolymus. Thus, this study aimed at providing scientific evidence of the antioxidant capacity of the aqueous extract of leaves of C. scolymus through various tests. Tests were conducted to study the antioxidant capacity in Saccharomyces cerevisiae proficient and deficient in antioxidant defenses, evaluation of antioxidant capacity in vitro method for 1,1-diphenyl-2-picrylhydrazyl (DPPH•), 2,2'azinobis-3-ethylbenzothiazoline-6-sulfonic acid (ABTS•+), inhibition of hydrogen peroxide and lipid peroxidation (TBARS) removal of the hydroxyl radical $(\mathrm{OH} \bullet)$, and inhibition of nitric oxide (NO). Furthermore, a quantitative study on the content of total phenolics, flavonoids and hydrolysable tannin was conducted to assess the contribution of these phenolics to the antioxidant capacity of the aqueous extract of $C$. scolymus.

\section{MATERIALS AND METHODS}

\section{Reagents}

Folin-ciocalteau reagent, aluminum chloride, potassium iodide, 2,2diphenyl-1-picrylhydrazyl radical (DPPH•), 2,2'-azinobis(3ethylbenzthiazoline-6-sulfonic acid) (ABTS), 6-hydroxy-2,5,7,8tetramethylchroman-2-carboxylic acid (Trolox), hydrogen peroxide, thiobarbituric acid, 2,2'azobis(2methylpropionamidine)dihydrochloride (AAPH) trichloroacetic acid, n-butanol, 2-deoxyribose, malonaldehyde, ferrous sulfate, phosphate buffer, phosphoric acid, sodium nitroprusside, Griess reagent, rutin, quercetin, gallic acid were purchased from Sigma (St. Louis, MO). All other reagents were of analytical grade.

\section{Plant material and preparation of extract}

The leaves of $C$. scolymus were provided by the processing industry of medicinal plants active life, located in the southeastern of Teresina city, Piauí, in August, 2012. The leaves of $C$. scolymus were dried at room temperature for 2 days and then crushed, milled in a knife mill to obtain $100 \mathrm{~g}$ and subsequently subjected to an extraction with water for $10 \mathrm{~min}$ by infusion (1/10, plant/solvent). After the treatment, the aqueous filtrate was frozen in liquid nitrogen and concentrated by lyophilization overnight for 3 days in order to obtain the aqueous extract of $C$. scolymus (AECS) in powder form. The yield of the extract under study was calculated by the following equation.

Yield $(\%)=\left(A_{1} \times 100\right) / A_{2}$

Where $A_{1}$ corresponds to the AECS lyophilized and $A_{2}$ correspond to the powdered dried plant material used for extraction with water.

\section{Determination of total phenols}

The total phenolic content of AECS was determined according to Singleton et al. (1999) by Folin-Ciocalteu spectrophotometric method, which involves the reduction of Folin-Ciocalteu reagent by phenolic compounds with concomitant formation of a blue colored complex. An aliquot of $200 \mu \mathrm{l}$ of AECS at $1000 \mu \mathrm{g} / \mathrm{ml}$ was mixed with $500 \mu \mathrm{l}$ of Folin-Ciocalteu reagent. Then the solution was stirred for $1 \mathrm{~min}$ and added $200 \mu \mathrm{l}$ of sodium carbonate (15\%). The mixture was allowed to stand and the absorbance was measured after $2 \mathrm{~h}$ of reaction in spectrophotometer at wave length from $750 \mathrm{~nm}$ (nanometers). The analysis was performed in triplicate and results were expressed in $\mathrm{mg}$ gallic acid equivalents per gram of extract (mg GAE/g E) using the calibration curve of gallic acid

$\left(y=0.121 x+0.011, r^{2}=0.9819\right)$.

\section{Determination of total flavonoid}

Total flavonoid content was determined by the formation of a complex of aluminum flavonoid using the methodology of Oyedemi et al. (2012). An aliquot of $200 \mu \mathrm{l}$ of AECS $(1000 \mu \mathrm{g} / \mathrm{ml})$ was mixed with $200 \mu \mathrm{l}$ of $20 \%$ aluminum chloride and two drops of acetic acid. The mixture was allowed to stand and the absorbance was measured after $40 \mathrm{~min}$ of reaction using spectrophotometer in length from $415 \mathrm{~nm}$. The analysis was performed in triplicate and results were expressed as total flavonoid rutin milligram equivalent per gram of extract ( $\mathrm{mg} \mathrm{R} / \mathrm{g} \mathrm{E}$ ) using the calibration curve of rutin 
$\left(y=0.0182 x-0.004, r^{2}=0.9949\right)$

\section{Determination of hydrolysable tannin}

The hydrolysable tannin content was determined from AECS using the potassium iodide test (Saad et al., 2012). To $3 \mathrm{ml}$ of the aqueous extract of AECS at $1000 \mu \mathrm{g} / \mathrm{ml}, 1 \mathrm{ml}$ of a saturated solution of potassium iodide was added and the mixture left to stand at room temperature for $40 \mathrm{~min}$. The absorbance was measured in a spectrophotometer at $550 \mathrm{~nm}$. The analysis was performed in triplicate and results were expressed in mg equivalent of gallic acid per gram of extract (mg GAE/g E) using the calibration curve of gallic acid $\left(y=0.121 x+0.011, r^{2}=0.9819\right)$.

\section{Antioxidant capacity by DPPH•}

It was done as per the methodology described by Silva et al. (2005) with some modifications. Stock solution of AECS $(250 \mu \mathrm{g} / \mathrm{ml})$, of $\mathrm{DPPH} \bullet(40 \mu \mathrm{g} / \mathrm{ml})$, and of the standard solutions of gallic acid $(250$ $\mu \mathrm{g} / \mathrm{ml})$, quercetin $(250 \mu \mathrm{g} / \mathrm{ml})$ and rutin $(250 \mu \mathrm{g} / \mathrm{ml})$ were prepared. Concentrations of $25,50,100,150$ and $200 \mu \mathrm{g} / \mathrm{ml}$ of AECS and standards were prepared by dilution. The reaction mixture $(0.3 \mathrm{ml}$ of extract with $2.7 \mathrm{ml}$ of a stock solution of $\mathrm{DPPH} \bullet$ ) was incubated at room temperature for $30 \mathrm{~min}$ and the absorbance was measured in a spectrophotometer at $517 \mathrm{~nm}$. The antioxidant evaluation was performed in triplicate and the absorbance values were converted into percentage of antioxidant capacity ( $\% A C)$ by the following equation.

$\% A C=[($ Control Abs. - Extract Abs. $) \times 100] /$ Control Abs

Where, Control Abs. is the initial absorbance of the ethanol solution of DPPH•, and Extract Abs. is the absorbance of the reaction mixture (DPPH + + extract). The inhibitory effective concentration $\left(\mathrm{EC}_{50}\right)$ needed to extract the DPPH radical• reduced by $50 \%$ was determined by probit regression (Locatelli et al., 2009).

\section{Antioxidant capacity by $\mathrm{ABTS} \bullet+$ method}

In order to determine the antioxidant capacity by the method of $\mathrm{ABTS}^{++}$, method described by $\mathrm{Re}$ et al. (1999) was used with modifications. Initially, a radical cation ABTS $\cdot{ }^{+}$was formed from the reaction of $5 \mathrm{ml}$ of a $7 \mathrm{mM} \mathrm{ABTS} \cdot{ }^{+}$solution with $88 \mu \mathrm{l}$ of $2.45 \mathrm{mM}$ potassium persulphate $\left(\mathrm{K}_{2} \mathrm{~S}_{2} \mathrm{O}_{8}\right)$ solution and incubated at room temperature in absence of light for $16 \mathrm{~h}$. After some time, a solution of ABTS.$^{+}$was diluted in ethanol to obtain a solution with absorbance of $0.70( \pm 0.05)$ to $734 \mathrm{~nm}$. The final concentrations of $25,50,100,150$ and $200 \mu \mathrm{g} / \mathrm{ml}$ of the AECS, gallic acid, quercetina and rutin were prepared. In dark environment, they were transferred at a rate of $40 \mu \mathrm{l}$ of each sample for test tubes with $1960 \mu \mathrm{l}$ of the radical ABTS.+. The absorbance readings, at times 1,4 and $6 \mathrm{~min}$, was done in a spectrophotometer at $734 \mathrm{~nm}$ and results were expressed in TEAC values (Trolox Equivalent Antioxidant Capacity) from a standard curve prepared with Trolox $\left(r^{2}=0.991\right)$. The standard curve was prepared by measuring the decrease in absorbance of the solution ABTS ${ }^{+}$with different concentrations of the Trolox (0.1 and $2 \mathrm{mM})$.

\section{Inhibition capacity of hydrogen peroxide $\left(\mathrm{H}_{2} \mathrm{O}_{2}\right)$}

The ability to inhibit $\mathrm{H}_{2} \mathrm{O}_{2}$ was determined according to the method of Ruch et al. (1989) with some modifications. A solution of $\mathrm{H}_{2} \mathrm{O}_{2}$ $(40 \mathrm{mM})$ and of AECS was formed in the same concentrations of $\mathrm{DPPH} \cdot$ and ABTS $\bullet+$ test in phosphate buffer $(\mathrm{pH} 7.4) .3 .5 \mathrm{ml}$ of AECS were added to $0.5 \mathrm{ml}$ of $\mathrm{H}_{2} \mathrm{O}_{2}$ and the values of the absorbances at time $10 \mathrm{~min}$ was determined in a spectrophotometer at $230 \mathrm{~nm}$. The absorbance of the mixture of the extract with $\mathrm{H}_{2} \mathrm{O}_{2}$ was converted to percent inhibition of hydrogen peroxide by the following equation.

$\%$ Inhibition of $\mathrm{H}_{2} \mathrm{O}_{2}=[($ Control Abs. - Extract Abs. $) \times 100] /$ Control Abs.

Where, Control Abs. is the initial absorbance of the solution of $\mathrm{H}_{2} \mathrm{O}_{2}$ and Extract Abs. is the absorbance of the reaction mixture $\left(\mathrm{H}_{2} \mathrm{O}_{2}+\right.$ extract).

\section{Evaluation of the capacity to inhibit lipid peroxidation (TBARS)}

The method used to evaluate the action of AECS in inhibiting lipid peroxidation, a major damage caused by reactive oxygen and nitrogen derivatives, was performed by the determination of substances reactive to thiobarbituric acid, known as TBARS method (Rosa et al., 2011). This method was used to measure the antioxidant capacity of AECS in a medium rich in lipids (Guimaraes et al., 2010). The lipid-rich substrate used was a homogenate of egg yolk $1 \%(\mathrm{w} / \mathrm{v})$ in $50 \mathrm{mM}$ phosphate buffer $(\mathrm{pH}$ 7.4). An aliquot of $0.5 \mathrm{ml}$ of the substrate was sonicated and homogenized with 0.1 $\mathrm{ml}$ of AECS in different concentrations $(25,50,100,150$ and 200 $\mu \mathrm{g} / \mathrm{ml}$ ). Lipid peroxidation was induced by adding $0.1 \mathrm{ml}$ of AAPH (dihydrochloride of 2,2'-azobis-2 metilpropinamide $0.12 \mathrm{M}$ ). The reactions were performed for $30 \mathrm{~min}$ at $37^{\circ} \mathrm{C}$. After cooling, samples $(0.5 \mathrm{ml})$ were centrifuged in $0.5 \mathrm{ml}$ of trichloroacetic acid $(15 \%)$ at $1,200 \times \mathrm{g}$ for $10 \mathrm{~min}$. An aliquot of $0.5 \mathrm{ml}$ of the supernatant was added to $0.5 \mathrm{ml}$ of thiobarbituric acid $(0.67 \%)$ and heated at $40^{\circ} \mathrm{C}$ for $15 \mathrm{~min}$. After heating, $2 \mathrm{ml}$ of $\mathrm{n}$-butanol were added to each test tube, then the tubes were shaken and centrifuged at $2000 \mathrm{rpm}$ for $10 \mathrm{~min}$. The absorbance of the samples was measured using a spectrophotometer at $532 \mathrm{~nm}$. The results were expressed as a percentage of TBARS formed from AAPH only control (induced). Rutin, quercetin, and gallic acid were used as positive control at concentrations of $200 \mu \mathrm{g} / \mathrm{ml}$.

Evaluation of the capacity of inhibiting the formation of hydroxyl radical $(\mathrm{OH} \bullet)$

The formation of hydroxyl radical from Fenton's reaction was measured using oxidative degradation of 2-deoxyribose (Moravia et al., 2011). The principle of the test is to quantify the degradation product of 2-deoxyribose in malonaldehyde (MDA) by its condensation with thiobarbituric acid (TBA). The reaction was initiated by the addition of $\mathrm{Fe}^{2+}\left(6 \mathrm{mM} \mathrm{FeSO}_{4}\right)$ to the solution containing $5 \mathrm{mM}$ of 2-deoxyribose, $100 \mathrm{mM}$ of $\mathrm{H}_{2} \mathrm{O}_{2}$ and $20 \mathrm{mM}$ phosphate buffer ( $\mathrm{pH}$ 7.4). To determine the antioxidant AECS against the hydroxyl radical, the AECS different concentrations (25, $50,100,150$ and $200 \mu \mathrm{g} / \mathrm{ml}$ ) were added to the system before addition of $\mathrm{Fe}^{2+}$. The reactions were performed for $15 \mathrm{~min}$ at room temperature and stationed by adding phosphoric acid, 4\% (v/v) followed by TBA $1 \%(\mathrm{w} / \mathrm{v}$ in $50 \mathrm{mM} \mathrm{NaOH})$. The solutions were heated for $15 \mathrm{~min}$ at $95^{\circ} \mathrm{C}$ and then cooled to room temperature. The absorbance was measured at $532 \mathrm{~nm}$ and results were expressed as equivalents of MDA formed by $\mathrm{Fe}^{2+}$ and $\mathrm{H}_{2} \mathrm{O}_{2}$. Rutin, quercetin, and gallic acid were used as positive control at concentrations of $200 \mu \mathrm{g} / \mathrm{ml}$.

\section{Evaluation of ability to inhibit formation of nitric oxide (NO)}

In this test, the nitric oxide (NO) is produced from the decomposition of sodium nitroprusside (SNP) in $20 \mathrm{mM}$ phosphate buffer ( $\mathrm{pH}$ 7.4). Once generated, NO interacts with oxygen to produce nitrite ions, which were measured by the Griess reaction (Basu and Hazra, 2006). The reaction mixture (1 ml) containing 10 
Table 1. Saccharomyces cerevisiae strains used in antioxidant evaluation.

\begin{tabular}{|c|c|c|c|}
\hline Description & Genotype & Deficiency in enzymatic defenses & Origin \\
\hline EG103 (Sod wt) & MATa leu2-3,112 trp1-289 ura3-52 & None & Edith Gralla, Los Angeles \\
\hline EG118 (Sod1 $\Delta)$ & Sod1::URA3 all other markers as EG103 & Cu-Zn superoxide dismutase (cystosolic) & Edith Gralla, Los Angeles \\
\hline EG110 (Sod2 $\Delta$ ) & Sod2::TRP1 all other markers as EG103 & Mn superoxide dismutase (mitocondrial) & Edith Gralla, Los Angeles \\
\hline EG133 (Sod1 $\Delta$ Sod2 $\Delta)$ & Sod1::URA3 Sod2::TRP1 double mutant all other markers as EG103 & Superoxide dismutase cystosolic and mitocondrial & Edith Gralla, Los Angeles \\
\hline EG223 (Cat1 $\Delta)$ & EG103, except Cat1:: TRP1 & Catalase cystosolic & Edith Gralla, Los Angeles \\
\hline EG $(\operatorname{Sod} 1 \Delta \operatorname{Cat} 1 \Delta)$ & EG103, except Sod1:: URA3 and Cat1::TRP1 & Cu-Zn superóxido dismutase e catalase citosólica & Edith Gralla, Los Angeles \\
\hline
\end{tabular}

$\mathrm{mM}$ of SNP in phosphate buffer and EACS at concentrations of $25,50,100,150$ and $200 \mu \mathrm{g} / \mathrm{ml}$, was incubated at $37^{\circ} \mathrm{C}$ for $1 \mathrm{~h}$. An aliquot of $0.5 \mathrm{ml}$ was taken and homogenized with $0.5 \mathrm{ml}$ of Griess reagent. The absorbance of the chromophore was measured at $540 \mathrm{~nm}$ in a spectrophotometer. The percentage inhibition of NO production was determined by comparing the absorbance values of the negative control (only $10 \mathrm{mM}$ SNP) and preparations of substances used in the test. The results were expressed as percentage of nitrite formed by SNP. Rutin, quercetin, and gallic acid were used as positive control at concentrations of $200 \mu \mathrm{g} / \mathrm{ml}$.

\section{Antioxidant capacity in S. cerevisiae cells}

To evaluate the antioxidant capacity of the AECS against oxidative damage induced by hydrogen peroxide, strains of $S$. cerevisiae proficient (Sod wt) and deficient (Sod1 $1 \Delta$ $\operatorname{Sod} 2 \Delta$, Sod $1 \Delta \operatorname{Sod} 2 \Delta$, Cat $1 \Delta$, Sod $1 \Delta \operatorname{Cat} 1 \Delta$ ) were used in antioxidant defense system. The methodology used was of the central disk, according to Fragoso et al. (2008), with modifications. The strains of $S$. cerevisiae proficient and deficient in superoxide dismutase (Sod) and catalase (Cat) were kindly provided by the research group in Genetic toxicology of Federal University of Rio Grande do Sul (UFRGS) and are described in Table 1.

Concentrations of $25,50,100,150$ and $200 \mu \mathrm{g} / \mathrm{ml}$ of AECS were used in this study. Three types of treatment for antioxidant evaluation were performed using the strains in the stationary phase $\left(2 \times 10^{8}\right.$ cells $\left./ \mathrm{ml}\right)$ of $S$. cerevisiae: pre-treatment, co-treatment and post-treatment. In the pretreatment, the concentrations of the extract were first added to a hard filter paper in center of plate yeast extractpeptone-dextrose (YEPD) and three hours later stressor hydrogen peroxide was added. In co-treatment the concentrations were added simultaneously to stressor hydrogen peroxide in disk filter paper. In the post-treatment hydrogen peroxide was first added and three hours later, the drug concentration. After $48 \mathrm{~h}$ incubation at $37^{\circ} \mathrm{C}$ the halo of growth inhibition in millimeters $(\mathrm{mm})$ was measured from the edge of the disc filter paper to the beginning of cell growth. The values can range from $0 \mathrm{~mm}$ (full growth) to $30 \mathrm{~mm}$ (no growth), these values being the size of a petri dish. All treatments were performed in triplicate. A each assessment, the strains were streaked on YEPD plate containing the center of a disc filter paper, to which $10 \mu \mathrm{l}$ extract is added and hydrogen peroxide $(40 \mathrm{mM})$. A control with only hydrogen peroxide was carried out for all strains of $S$. cerevisiae.

\section{Statistical analysis}

The antioxidant result is the value of mean + standard deviation (SD) of three experiments, and each experiment was performed in triplicate for each treatment. Statistica analysis was performed using analysis of variance (ANOVA) and significant differences between means were determined by Tukey's test, using the GraphPad Prism 5.01. The values of $p<0.05$ were considered significantly different. To evaluate the relationship between tota phenolic content and antioxidant capacity, Pearson correlation coefficient was calculated with $95 \%$ confidence using the GraphPad Prism 5.01.

\section{RESULTS AND DISCUSSION}

\section{Determination of phenols, flavonoids and hydrolysable tannin}

With $18 \%$ of yield, the results of the phytochemical analysis showed the quantitative values of AECS $661.15 \pm 20.11 \mathrm{mg} \mathrm{GAE} / \mathrm{g} E$ to phenolic compound, $123.96 \pm 12.47 \mathrm{mg} \mathrm{R} / \mathrm{g} \mathrm{E}$ to flavonoids and $14.25 \pm 3.18 \mathrm{mg} \mathrm{GAE} / \mathrm{g} \mathrm{E}$ to hydrolysable tannin. These results demonstrate that the AECS has high quantities of phenolic compounds. Other studies have performed the quantification of phenolic compounds and flavonoids in methanolic and ethanolic extract of leaves of $C$. scolymus, however, in smaller quantities compared to our results for both phenolic and flavonoids compounds (Llorach et al., 2002; Wang et al., 2003; Gouveia and Castilho, 2012; Nassar et al., 2013).

The content of phenolic compounds found in plants may vary during processing steps such as growing, harvesting, storage and technological procedures used (Gil-Izquierdo et al., 2001; Fratianni et al., 2007; Lombardo et al., 2010). The C. scolymus is a plant rich in phenolic compounds among which are caffeic, coumarin, hydroxybenzoic and hydroxycinnamic, ferulic and gallic (Hammouda et al., 1991; Fratianni et al., 2007; Seneviratne and Kotuwegedara, 2009; Nassar et al., 2013; Abu-Reidah et al., 2013; Zan et al., 2013; Palermo et al., 2013). The phenolic compounds present in plants have received great attention because of their antioxidant properties and they can potentially interact with biological systems and play an important role in anticancer, anti-inflammatory and antimicrobial activity (AbuReidah et al., 2013; Wang et al., 2003). The 
Table 2. Antioxidant capacity of the aqueous extract of Cynara scolymus, rutin, quercetin and gallic acid by the DPPH• method.

\begin{tabular}{|c|c|c|c|c|}
\hline \multirow{2}{*}{ Concentration $(\mu \mathrm{g} / \mathrm{ml})$} & \multirow{2}{*}{ Cynara scolymus } & \multicolumn{2}{|c|}{ Antioxidant capacity (\%) } & \multirow{2}{*}{ Gallic acid } \\
\hline & & Rutin & Quercetin & \\
\hline 25 & $11.26 \pm 1.07^{\mathrm{abc}}$ & $25.37 \pm 2.15$ & $55.99 \pm 2.15$ & $89.87 \pm 0.83$ \\
\hline 50 & $27.02 \pm 1.75^{\mathrm{bc}}$ & $32.65 \pm 1.77$ & $79.59 \pm 0.97$ & $92.95 \pm 0.10$ \\
\hline 100 & $49.69 \pm 1.85^{\mathrm{bc}}$ & $37.96 \pm 0.36$ & $81.50 \pm 0.25$ & $93.19 \pm 0.06$ \\
\hline 150 & $72.10 \pm 1.06^{\mathrm{bc}}$ & $60.85 \pm 6.33$ & $81.87 \pm 0.21$ & $93.71 \pm 0.15$ \\
\hline 200 & $83.40 \pm 0.19^{\mathrm{C}}$ & $64.22 \pm 1.76$ & $82.18 \pm 0.15$ & $93.95 \pm 0.47$ \\
\hline $\mathrm{CE}_{50}$ & 100.70 & 111.96 & 10.25 & 1.20 \\
\hline
\end{tabular}

${ }^{\mathrm{a}}$ significant $(P<0.05)$ in relation to rutin. ${ }^{\mathrm{b}}$ significance $(P<0.05)$ in relation to quercetin. ${ }^{\mathrm{c}}$ significance $(P<0.05)$ in relation to gallic acid.

Table 3. Trolox equivalent antioxidant capacity (TEAC) of the aqueous extract of Cynara scolymus, rutin, quercetin and gallic acid.

\begin{tabular}{lccc}
\hline \multirow{2}{*}{ Sample } & \multicolumn{3}{c}{ TEAC, $\mathbf{~ m M ~ o f ~ T r o l o x ~}$} \\
\cline { 2 - 4 } & $\mathbf{1} \mathbf{~} \mathbf{~ i n}$ & $\mathbf{4} \mathbf{~}$ in & $\mathbf{6} \mathbf{~ m i n}$ \\
\hline Cynara scolymus & $3.45 \pm 0.26^{\mathrm{C}}$ & $4.53 \pm 0.15^{\mathrm{C}}$ & $5.88 \pm 0.11^{\mathrm{C}}$ \\
Rutin & $1.45 \pm 0.10$ & $1.75 \pm 0.10$ & $1.89 \pm 0.05$ \\
Quercetin & $3.76 \pm 0.11$ & $5.01 \pm 0.23$ & $6.05 \pm 0.25$ \\
Gallic acid & $8.03 \pm 0.13$ & $12.84 \pm 0.08$ & $13.21 \pm 0.03$ \\
\hline
\end{tabular}

${ }^{\mathrm{a}}$ significance $(P<0.05)$ in relation to rutin. ${ }^{\mathrm{b}}$ significance $(P<0.05)$ in relation to quercetin. ${ }^{\text {'significance }}(P<0.05)$ in relation to gallic acid.

antioxidant properties are attributed to flavonoids due to their hydroxyl groups that can act as free radical scavengers, reducing agents and metal chelation (Agati et al., 2012). Flavonoids are natural chemical constituents which may be found in larger quantities and play an important role in the pharmacological properties attributed to C. scolymus (Häusler et al., 2002; Zhu et al., 2004; Pandino et al., 2011). Among the flavonoids already found in extracts of C. scolymus may be cited luteolin, apigenin, myricetin, quercetin and rutin (Zan et al., 2013; Palermo et al., 2013).

\section{Antioxidant capacity by DPPH・ method}

The DPPH• is a stable organic radical which has been widely used in studies to evaluate the antioxidant capacity of plant extracts or pure compounds. In this method, the antioxidant capacity is determined by the analysis of the decrease of absorbance of DPPH solution at $517 \mathrm{~nm}$ in a spectrophotometer, in which the $\mathrm{DPPH}$ radical of purple color is reduced to form $\mathrm{DPPH}_{2}$ of yellow (Mishra et al., 2012). Therefore, the AECS showed good antioxidant capacity by reducing $\mathrm{DPPH} \bullet$ radical in a concentration-dependent manner (Table 2), wherein the values in percent of the antioxidant capacity of AECS at concentrations of 100,150 and $200 \mu \mathrm{g} / \mathrm{ml}$ were significantly superior $(p<0.05)$ when compared to the values of antioxidant capacity of rutin at the same concentrations. When the antioxidant capacity of AECS is compared with the positive control quercetin at the concentrations of $25,50,100$ and $150 \mu \mathrm{g} / \mathrm{ml}$, it is observed that the values were significantly lower $(p<$ 0.05). In contrast, at the concentration of $200 \mu \mathrm{g} / \mathrm{ml}$, the AECS presented antioxidant capacity higher than quercetin. Compared to the control gallic acid, the values of antioxidant capacity at the concentrations of 25,50 , 100,150 and $200 \mu \mathrm{g} / \mathrm{ml}$ were significantly lower $(p<$ 0.05 ). The results of the $E_{50}$ of AECS, rutin, quercetin and gallic acid are shown in Table 2, being observed that the AECS was more effective in reducing of DPPH• radical than the control rutin.

The evaluation of antioxidant by DPPH $\bullet$ method has already been accomplished by Llorach et al. (2002) with the AECS using only the concentration of $10 \mu \mathrm{g} / \mathrm{ml}$ and with the reaction time of $1 \mathrm{~h}$. In another study by Wang et al. (2003), it was shown that the extracts of three different varieties of $C$. scolymus presented good antioxidant capacity against $\mathrm{DPPH} \cdot$ radical, which was attributed to the phenolic compounds with correlation $r^{2}=0.96$. Zan et al. (2013) using the AECS also achieved satisfactory results for the antioxidant capacity by the method of $\mathrm{DPPH} \bullet$.

\section{Antioxidant capacity by the method of ABTS•+}

Like DPPH $\bullet$, the method ABTS •+ or TEAC is widely used to evaluate the antioxidant capacity of a variety of substances including plant extracts. The TEAC values of the AECS were obtained at three different times and compared to the TEAC of positive control rutin, quercetin and gallic acid (Table 3 ). As shown in Table 3, the values of TEAC of the AECS for the times of 1,4 and 6 min were significantly $(p<0.05)$ higher when compared with the TEAC of the positive control rutin. Regarding the TEAC values of quercetin and gallic acid for the times 1, 4 and 6 min, it was observed that the TEAC values of the AECS 


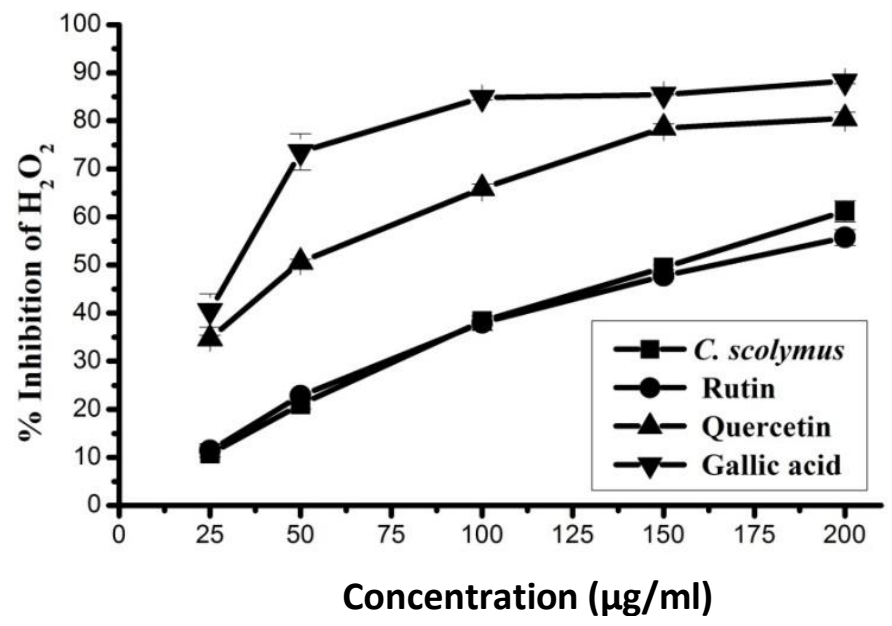

Figure 1. Percent inhibition of hydrogen peroxide from the aqueous extract of Cynara scolymuse of positive controls rutin, quercetin and gallic acid.

Each value represents the mean \pm standard deviation $(n=3)$.

were lower, however, only relative to gallic acid was observed significant difference $(p<0.05)$. The TEAC value takes into account the capacity of a substance to react with ABTS •+ radical (Arts et al., 2004). Thus, this study demonstrated that the AECS was capable of reacting with the ABTS $\bullet+$ radical, showing antioxidant capacity better than rutin. Wang et al. (2003) using only the concentration of $10 \mu \mathrm{g} / \mathrm{ml}$ also showed antioxidant activity against $A B T S \cdot+$ radical. Betancor-Fernández et al. (2003) also evaluated the antioxidant capacity of the AECS by the TEAC method and the results obtained were similar to those in this study.

\section{Inhibition capacity of $\mathrm{H}_{2} \mathrm{O}_{2}$}

Hydrogen peroxide is a type of ROS which can be formed in vivo by many oxidizing enzymes, through the membranes and slowly oxidize a large number of biological molecules (Halliwell, 1991). The capacity of AECS to inhibit the hydrogen peroxide was determined according to the method of Ruch et al. (1989) and the results were $10.75 \pm 0.61,21.0 \pm 0.97,38.34 \pm 0.89$, $49.50 \pm 0.46$ and $61.18 \pm 2.20 \%$ for concentrations of 25 , $50,50,100,150$ and $200 \mu \mathrm{g} / \mathrm{ml}$, respectively (Figure 1). The AECS was able to inhibit the hydrogen peroxide in a concentration-dependent manner, and the results of AECS were significantly lower $(p<0.05)$ in relation to results of quercetin and gallic acid. Furthermore, the results of AECS at concentrations higher than $100 \mu \mathrm{g} / \mathrm{ml}$ were superior to those of rutin, which showed values $11.47 \pm 1.42,22.83 \pm 0.54,37.98 \pm 1.57,47.78 \pm 0.33$ and $55.73 \pm 1.60 \%$ of inhibition of hydrogen peroxide in concentrations of $25,50,50,100,150$ and $200 \mu \mathrm{g} / \mathrm{ml}$, respectively. No other study that addresses the action of AECS in the inhibition of the hydrogen peroxide was found, which makes this study the first.

\section{Inhibition of lipid peroxidation (TBARS)}

Free radicals are responsible for the chain reactions that cause lipid oxidation, inducing functional loss of biomembranes and various types of damage to essential biological molecules such as proteins and nucleic acid bases and, thus, having been implicated in the pathogenesis of various diseases (Niki, 2009). The TBARS method has been widely used to evaluate the extent of the in vitro lipid peroxidation, in which the oxidation of unsaturated fatty acids occurs from a source rich in lipids (Niki, 2010). Thus, the AECS at concentrations of 25, 50, $50,100,150$ and $200 \mu \mathrm{g} / \mathrm{ml}$ was able to prevent lipid peroxidation by reduction of the levels of TBARS in 83.5, $83.95,84.57,86.56$ and $87.6 \%$ (Figure 2). Similar results were obtained with the controls rutin, quercetin and gallic acid, which decreased the levels of TBARS in 85.25, 87.13 and $85.15 \%$, respectively (Figure 2 ). As the positive controls, rutin, quercetin and gallic acid, the AECS significantly $(p<0.05)$ reduced the levels of TBARS formed by AAPH.

The percentage of inhibition of peroxidation shown in this study decreased according to the increase in the concentration of AECS. Besides, the concentration of 200 $\mu \mathrm{g} / \mathrm{ml}$ presented a result of inhibition of lipid peroxidation greater than the controls rutin, quercetin, and gallic acid. Thus, the AECS may be considered as a good inhibitor of lipid peroxidation in this experimental model. In addition, studies that have used the TBARS method for evaluation of the inhibition of lipid peroxidation by AECS were not found. However, one study was conducted with AECS, whose capacity to inhibit lipid peroxidation was demonstrated through ferric thiocyanate method (Wang et al., 2013).

\section{Inhibition of hydroxyl radical $(\mathrm{OH} \bullet)$}

Among the ROS, hydroxyl radicals are the more reactive, being that these radicals can react with a wide variety of biomolecules and consequently induce severe cell damage and mutation, cell death, carcinogenesis and aging (Li et al., 2013). In the present study, the hydroxyl radicals were generated from the Fenton reaction, and as shown in Figure 3, the AECS at concentrations of 25, 50 , 100,150 and $200 \mu \mathrm{g} / \mathrm{ml}$ was able to significantly remove the hydroxyl radical $(p<0.05)$ (Figure 3$)$. At the concentration of $200 \mu \mathrm{g} / \mathrm{ml}$, the positive controls rutin, quercetin and gallic acid presented the values 59.02, 52.77 and $64.75 \%$ of inhibition of the hydroxyl radical, respectively (Figure 3 ). According to these results, the AECS may be considered a good hydroxyl radical inhibitor. 


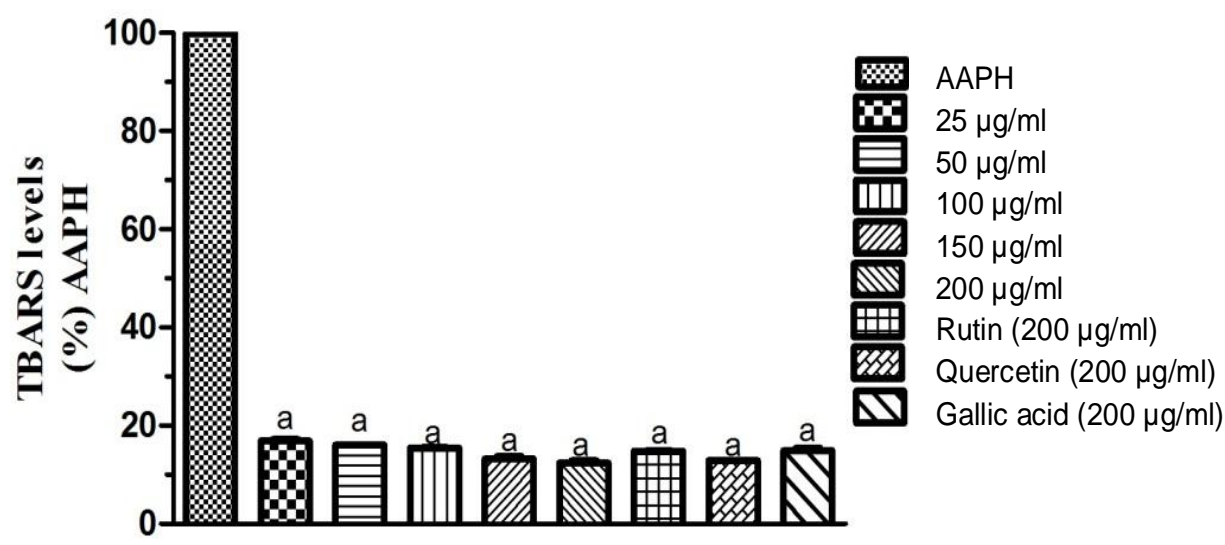

Figure 2. Inhibition of TBARS formed in vitro by AECS, rutin, quercetin, and gallic acid. Each value represents the mean \pm standard deviation $(n=3)$. The significance $(P<0.05)$ is relative to vehicle AAPH.

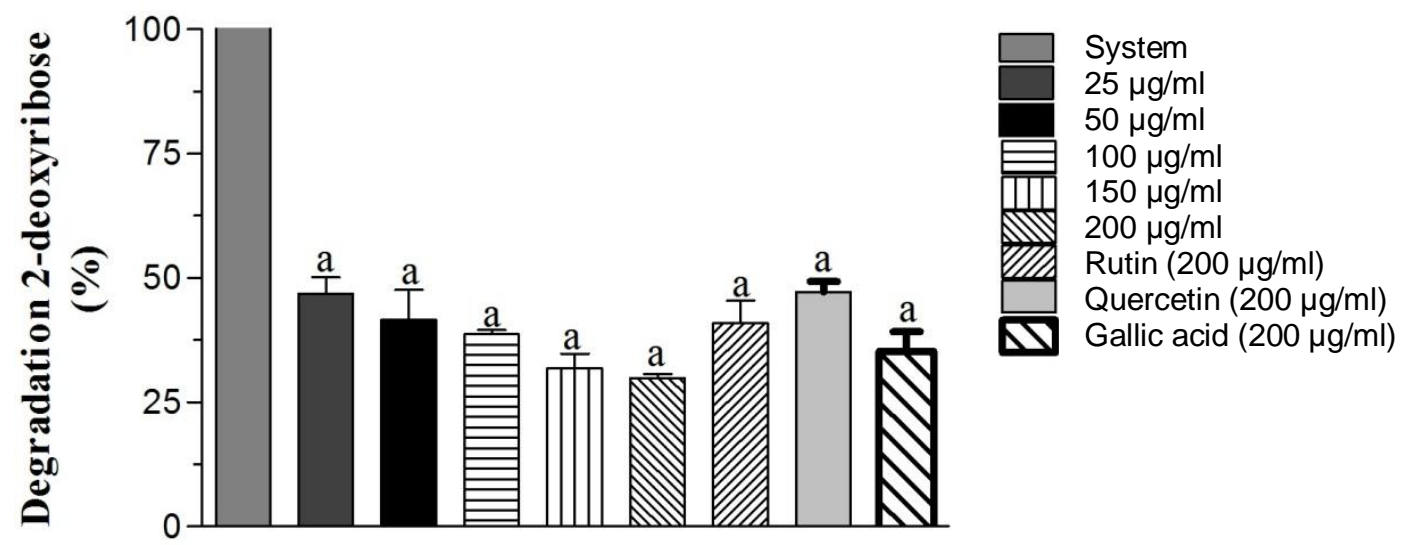

Figure 3. Inhibiting the formation of hydroxyl radical by AECS, rutin, quercetin and gallic acid. Each value represents the mean \pm standard deviation $(n=3)$. The significance $(P<0.05)$ compared to the System (does not contain the AECS).

inhibitor. The innovator character of this study can be expressed by the absence of reports that evaluate the antioxidant capacity of AECS in the inhibition of the hydroxyl radical.

\section{Inhibition of nitric oxide (NO)}

Nitric oxide is considered species reactive derivative of nitrogen, which if produced in excess can contribute to the development of pathologies such as chronic inflammation, cancer and autoimmune diseases (Muntane et al., 2013). The measure of antioxidant capa-city by the elimination of nitric oxide was based on the principle that the sodium nitroprusside (SNP) in aqueous solution at physiological $\mathrm{pH}$ spontaneously generates nitric oxide, which interacts with oxygen to produce nitrite ions $\left(\mathrm{NO}_{2}{ }^{-}\right)$, which can be calculated by means of the Griess reagent. Thus, the AECS showed inhibitory capacity of nitric oxide generated by sodium nitroprusside, as for the concentrations of $25,50,100,150$ and $200 \mu \mathrm{g} / \mathrm{ml}$, the values in percentage were $73.17,77.46,78.95,79.42$ and $80.18 \%$, respectively (Figure 4). These outcomes also demonstrate a concentration-dependent and significantly $(p<0.50)$ different inhibitory capacity of AECS relative to SNP. When the inhibition of nitric oxide is compared with the controls rutin $(79.25 \%)$, quercetin $(76.8 \%)$ and gallic acid $(74.62 \%)$, the concentrations of 150 and $200 \mathrm{mg} / \mathrm{ml}$ of AECS exhibited superior results than the positive controls. Thus, the extract of the $C$. scolymus at study can be considered as a good inhibitor of nitric oxide. Like the methods for evaluating of inhibition of 


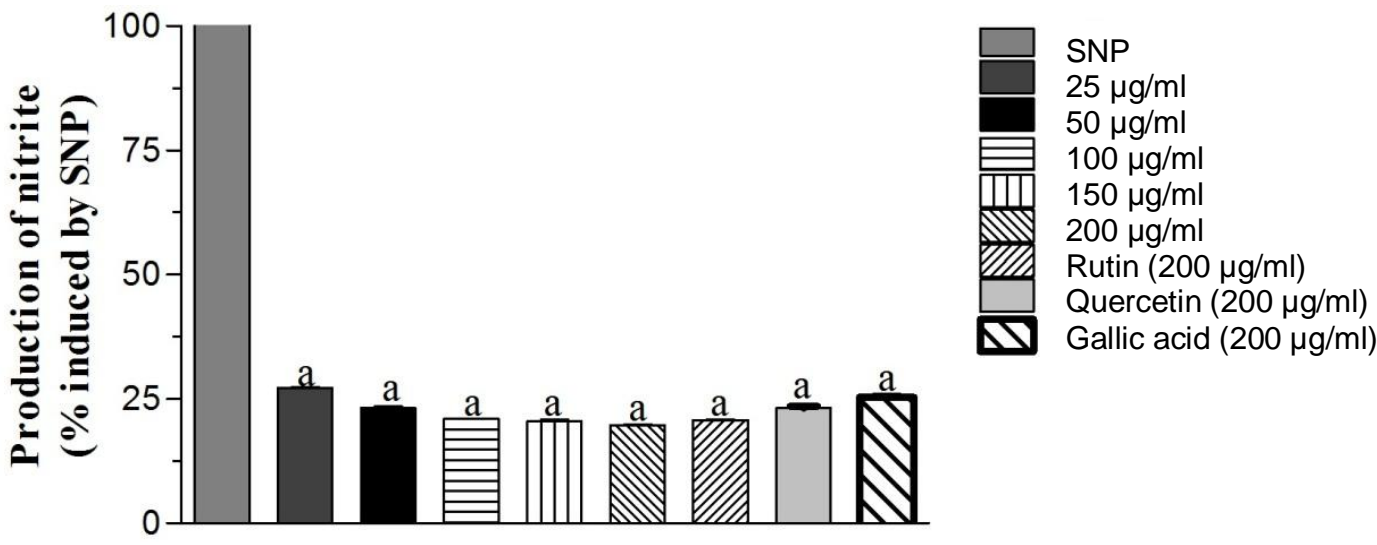

Figure 4. Inhibition of nitric oxide by AECS, rutin, quercetin, and gallic acid. Each value represents the mean \pm standard deviation $(\mathrm{n}=3)$. The significance $(P<0.05)$ compared to SNP.

Table 4. Pearson correlation coefficient $(r)$ between the content of phenolic compounds and antioxidant capacity.

\begin{tabular}{lcc}
\hline Correlation & $\boldsymbol{r}$ & $\boldsymbol{r}(\%)$ \\
\hline Total phenols vs. DPPH• & 0.989 & 98.9 \\
Total phenols vs. ABTS•+ & 0.992 & 99.2 \\
Total phenols vs. Inhibition of $\mathrm{H}_{2} \mathrm{O}_{2}$ & 0.983 & 98.3 \\
Total phenols vs. TBARS & 0.984 & 98.4 \\
Total phenols vs. Hydroxyl & 0.960 & 96.0 \\
Total phenols vs. Nitrito & 0.854 & 85.4 \\
\hline
\end{tabular}

Table 5. Pearson correlation coefficient $(r)$ between the different evaluation methodologies for antioxidant capacity.

\begin{tabular}{|c|c|c|}
\hline Correlation & $r$ & $r(\%)$ \\
\hline $\mathrm{DPPH} \bullet v s . \mathrm{ABTS} \bullet+$ & 0.999 & 99.9 \\
\hline $\mathrm{DPPH} \cdot v s$. Nitrite & 0.899 & 89.9 \\
\hline $\mathrm{DPPH} \cdot v s . \mathrm{TBARS}$ & 0.966 & 96.6 \\
\hline DPPH・vs. Hydroxyl & 0.971 & 97.1 \\
\hline DPPH・ vs. Inibition of $\mathrm{H}_{2} \mathrm{O}_{2}$ & 0.996 & 99.6 \\
\hline ABTS•+ vs. Nitrito & 0.943 & 94.3 \\
\hline ABTS $\bullet+v s$. TBARS & 0.996 & 99.6 \\
\hline ABTS•+ vs. Hidroxila & 0.875 & 87.5 \\
\hline ABTS $\bullet+$ vs. Inhibition of $\mathrm{H}_{2} \mathrm{O}_{2}$ & 0.991 & 99.1 \\
\hline Nitrite vs. TBARS & 0.785 & 78.5 \\
\hline Nitrite vs. Inibition of $\mathrm{H}_{2} \mathrm{O}_{2}$ & 0.925 & 92.5 \\
\hline Nitrite vs. Hidroxila & 0.893 & 89.3 \\
\hline Hydroxyl vs. TBARS & 0.964 & 96.4 \\
\hline Hydroxyl vs. Inhibition of $\mathrm{H}_{2} \mathrm{O}_{2}$ & 0.960 & 96.0 \\
\hline
\end{tabular}

hydrogen peroxide and hydroxyl radical, the study presents itself as the first report on the evaluation of AECS in the inhibition of nitric oxide.

\section{Correlation between the total phenolic content and antioxidant capacity}

Phenolic compounds represent an important class of antioxidant compounds which are found in many plants. In this context, the correlation between the concentration of total phenolics and antioxidant capacity has been widely studied involving extracts of plants (Mulinacci et al., 2004; Wang et al., 2003; Llorach et al., 2002; Toma et al., 2013). Studies involving extracts of $C$. scolymus demonstrated that there is a linear correlation between phenolic content and antioxidant capacity (Mulinacci et al., 2004; Toma et al., 2013). In order to determine the contribution of the phenolic content in AECS on antioxidant capacity, the Pearson correlation coefficient ( $r$ ) was determined. According to the results, strong positive correlations were observed between the concentration of phenolic content and antioxidant capacity of all antioxidants in vitro methods (Table 4). Therefore, the results suggest that phenolic compounds may exert an important contribution to in vitro antioxidant capacity of the AECS. The highest correlations were observed for the in vitro antioxidant methods $\mathrm{DPPH} \cdot$ and ABTS -+, in which the two organic radicals are easily reduced in the presence of phenolic compounds. Phenolic compounds have been mainly responsible for the antioxidant capacity of natural extracts and probably due to their redox properties, they act as reducing agents, hydrogen donors and singlet oxygen scavengers (Letelier et al., 2008).

Although the mechanisms of reactions are different for the antioxidant evaluation methods employed in this work, a correlation between the in vitro results for the antioxidant capacity was determined and it is shown in Table 5. Positive correlations $(r>0)$ were observed between the antioxidants results, indicating that the antioxidants in vitro methods provide comparable values when they are used to determine the antioxidant capacity 

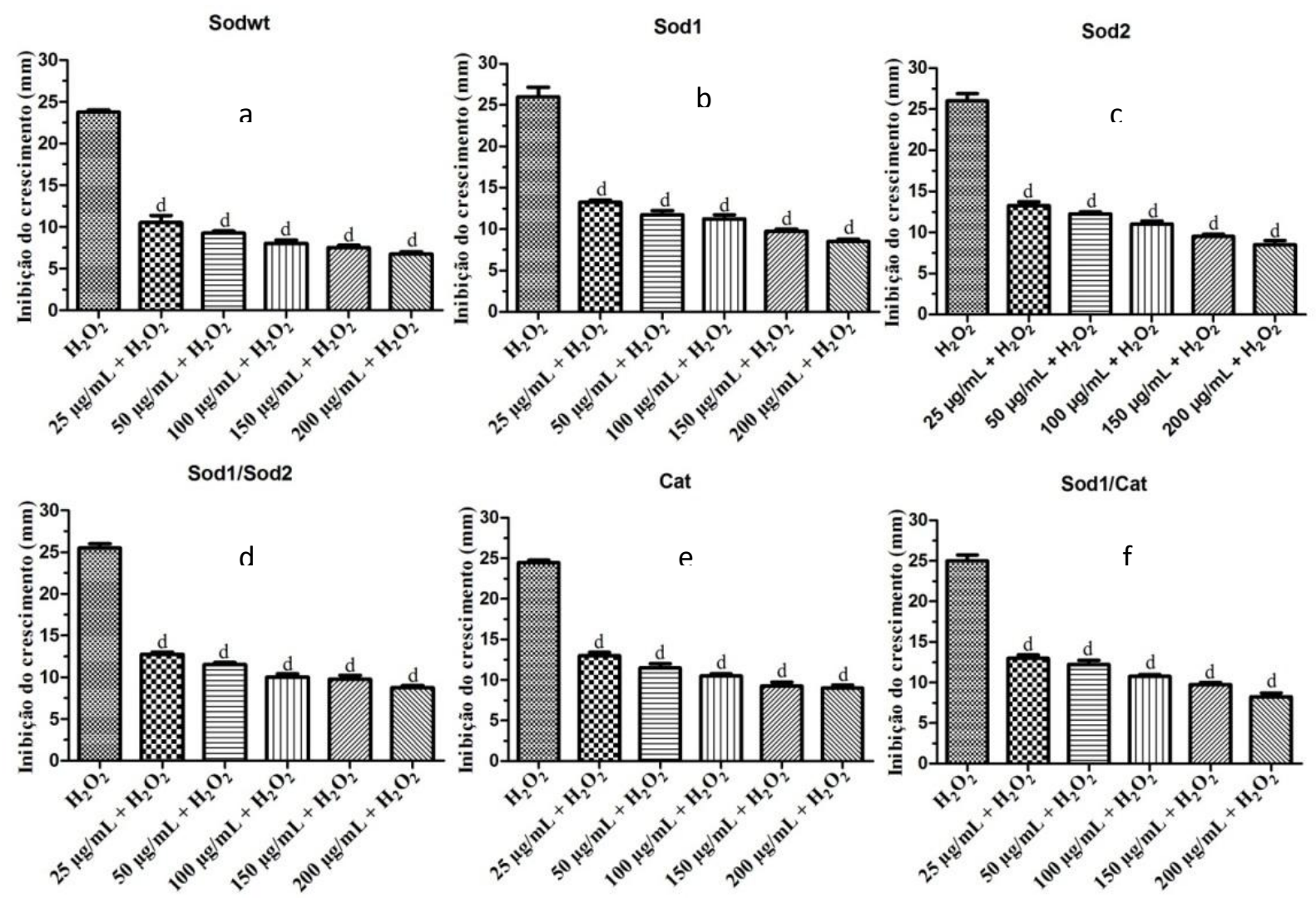

Figure 5. Antioxidant capacity of the aqueous extract Cynara scolymus against oxidative damage induced in strains of Saccharomyces cerevisiae pre-treatment. Significance $(P<0.05)$ compared to the stressor $\left(\mathrm{H}_{2} \mathrm{O}_{2}\right)$.

of AECS. The best correlation was for DPPH $\bullet$ vs. ABTS •+ in which the two tests have the same mechanism in a reaction with a substance which has antioxidant properties. The lowest correlation was found for inhibition of nitric oxide vs. TBARS, however, the results on AECS antioxidants are still considered a good correlation.

\section{Antioxidant capacity in strains of $\mathbf{S}$. cerevisiae}

In the pre-treatment, co-treatment and post-treatment (Figures 5 and 6), it was possible to observe a trend to decrease in growth inhibition and the consequent increase in survival of strains of $S$. cerevisiae (wt Sod, Sod1 $\Delta$, $\operatorname{Sod} 2 \Delta, \operatorname{Sod} 1 \Delta \operatorname{Sod} 2 \Delta, \operatorname{Cat} 1 \Delta, \operatorname{Sod} 1 \Delta \operatorname{Cat} 1 \Delta)$ at all concentrations of AECS was statistically significant $(p<$ $0.05)$ compared to the results on stressor hydrogen peroxide. In the pre-treatment and co-treatment, the AECS showed significant antioxidant capacity for all strains of $S$. cerevisiae in a dose-dependent manner, inhibiting the oxidative effect of hydrogen peroxide and allowing the enhancement of the survival of strains tested. The concentration of $200 \mu \mathrm{g} / \mathrm{ml}$ was the most protective having the greatest antioxidant capacity, indicating that higher concentrations of $A E C S$ are required to nullify required to nullify the oxidizing effects of hydrogen peroxide. The strain of $S$. cerevisiae wild (Sodwt) showed a higher level of survival in the pre-treatment and cotreatment, while the strains of $S$. cerevisiae deficient in antioxidant defenses were more sensitive to hydrogen peroxide, suggesting the importance of superoxide dismutase in cellular protection against oxidative stress. Importantly, antioxidant capacity, was observed on AECS Sodwt lineage as well as in strains deficient in superoxide dismutase (Sod $1 \Delta$, Sod $2 \Delta$ and $\operatorname{Sod} 1 \Delta \operatorname{Sod} 2 \Delta)$, which suggests that the protective effect may increase the activity of superoxide dismutase, demonstrating the key role of the aqueous extract of the leaves of $C$. scolymus in cellular antioxidant defense. In addition, the protection afforded against hydrogen peroxide seems to be also required for the double mutant strain and mutant Cat $1 \Delta$ Sod $1 \Delta$ Cat $1 \Delta$ because they were able to acquire tolerance to oxidative stress with decreasing inhibition of growth in pre-treatment and co-treatment.

In the post-treatment (Figure 7), the strains of $S$. cerevisiae were first exposed to oxidative damage caused by hydrogen peroxide, and after three hours the AECS was added at various concentrations for the verification of the behavior of strains of $S$. cerevisiae. The data obtained in the post-treatment showed a behavior similar to the pre- 

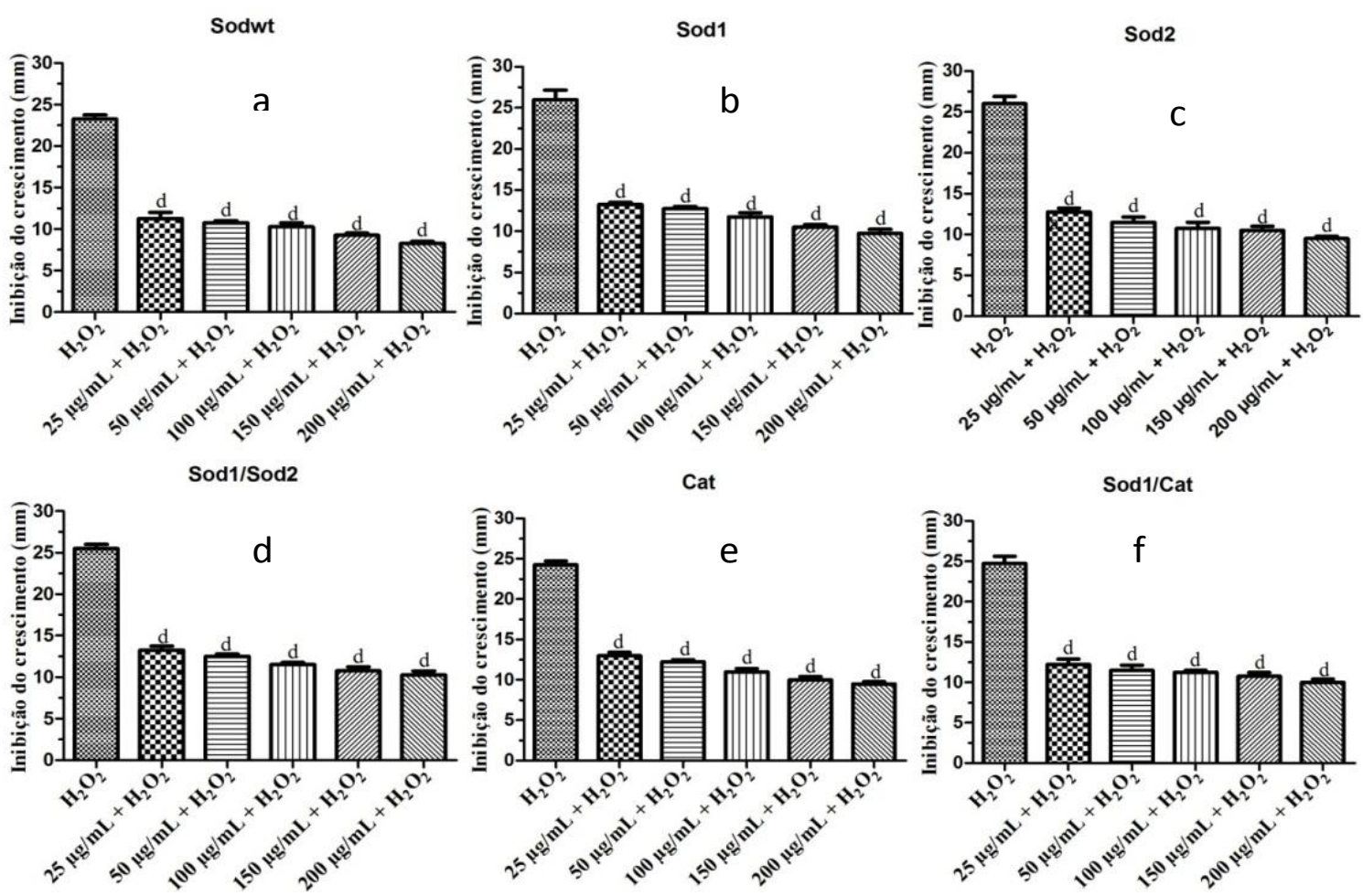

Figure 6. Antioxidant capacity of the aqueous extract of Cynara scolymus against oxidative damage induced in strains of Saccharomyces cerevisiae co-treatment. Significance $(P<0.05)$ compared to the stressor $\left(\mathrm{H}_{2} \mathrm{O}_{2}\right)$.
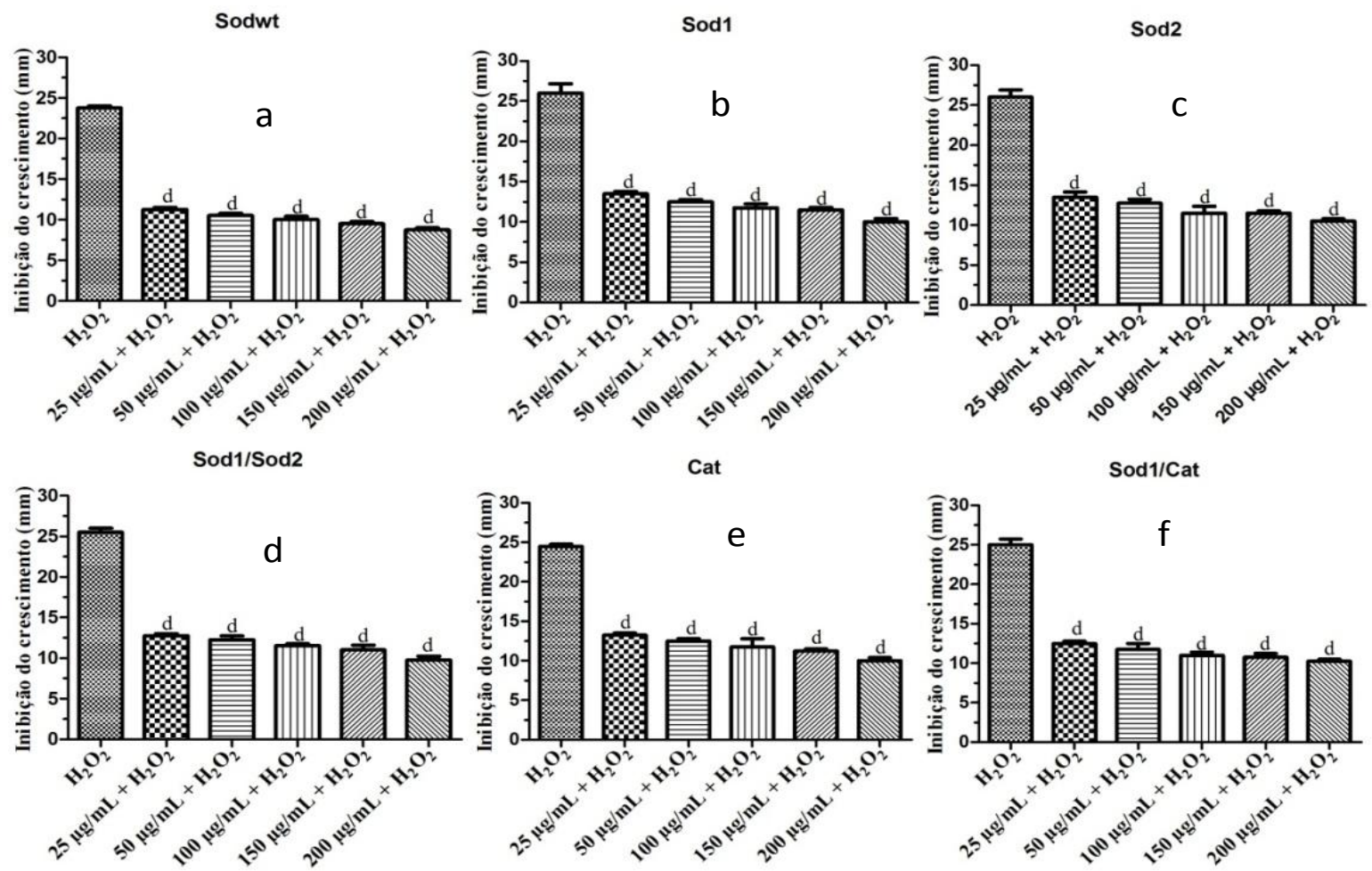

Figure 7. Antioxidant capacity of the aqueous extract of Cynara scolymus against induced oxidative damage in lines Saccharomyces cerevisiae after treatment. Significance $(P<0.05)$ compared to the stressor $\left(\mathrm{H}_{2} \mathrm{O}_{2}\right)$. 
treatment and co-treatment, where the strains of $S$. cerevisiae in the presence of AECS showed an increase in survival rate with a decrease in growth inhibition at all concentrations tested as compared with the results of stressor hydrogen peroxide. It can also be observed that the strain of $S$. cerevisiae wild (Sodwt) was the one with the lowest rate of growth inhibition when compared with the mutant strains. The strains Sod1 $\Delta$ and Sod2 $\Delta$ Sod1 $\Delta \operatorname{Sod} 2 \Delta$ also had an increased survival with decreased growth inhibition when post-treated with the AECS at concentrations of 25, 50, 100, 150 and 200 $\mu \mathrm{g} / \mathrm{ml}$. This antioxidant effect is also evident for the mutant and double mutant $\operatorname{Cat} 1 \Delta$ and $\operatorname{Sod} 1 \Delta \operatorname{Cat} 1 \Delta$ at all concentrations tested significantly $(p<0.05)$ in comparison to the results on hydrogen peroxide. In addition, all strains of $S$. cerevisiae showed a lower rate of inhibition at a concentration of $200 \mu \mathrm{g} / \mathrm{ml}$ compared with the inhibition induced by hydrogen peroxide.

\section{Conclusion}

The results obtained in the present work clearly indicate that AECS has considerable antioxidant capacity in vitro and in strains of $S$. cerevisiae. The antioxidant capacity of this extract can be attributed to the phenolic compounds in accordance with the correlations made with the in vitro evaluation of antioxidant capacity. Consequently, our results suggest that the aqueous extract may be used as a natural source of antioxidants, since there is a current need for the provision of new bioactive molecules derived from plants to the development of new drugs with antioxidant.

\section{REFERENCES}

Abu-Reidah IM, Arráez-Román D, Segura-Carretero A, FernándezGutiérrez A (2013). Extensive characterisation of bioactive phenolic constituents from globe artichoke (Cynara scolymus L.) by HPLCDAD-ESI-QTOF-MS. Food Chem. 141(3):2269-2277.

Agati G, Azzarello E, Pollastri S, Tattini M (2012). Flavonoids as antioxidants in plants: Location and functional significance. Plant Sci. 196(0):67-76.

Arts MJTJ, Sebastiaan Dallinga J, Voss H-P, Haenen GRMM, Bast A (2004). A new approach to assess the total antioxidant capacity using the TEAC assay. Food Chem. 88(4):567-570.

Basu S, Hazra B (2006). Evaluation of nitric oxide scavenging activity, In Vitro and Ex Vivo, of selected medicinal plants traditionally used in inflammatory diseases. Phytother. Res. 20(10):896-900.

Betancor-Fernández A, Pérez-Gálvez A, Sies H, Stahl W (2003). Screening pharmaceutical preparations containing extracts of turmeric rhizome, artichoke leaf, devil's claw root and garlic or salmon oil for antioxidant capacity. J. Pharm. Pharmacol. 55(7):981-986.

Bhattacharya S, Ahmed KKM, Chakraborty S (2011). Free Radicals Cardiovascular Diseases: An Update. Free Radic Antiox. 1(1):17-22.

Bundy R, Walker AF, Middleton RW, Wallis C, Simpson HCR (2008). Artichoke leaf extract (Cynara scolymus) reduces plasma cholesterol in otherwise healthy hypercholesterolemic adults: A randomized, double blind placebo controlled trial. Phytomedicine 15(9):668-675.

Dizdaroglu $M$, Jaruga $P$, Birincioglu $M$, Rodriguez H (2002). Free radical-induced damage to DNA: mechanisms and measurement. Free Radic. Biol. Med. 32(11):1102-1115.
Fadel O, El Kirat K, Morandat S (2011). The natural antioxidant rosmarinic acid spontaneously penetrates membranes to inhibit lipid peroxidation in situ. Biochim. Biophys. Acta. 1808(12):2973-2980.

Fragoso V, Nascimento NCd, Moura DJ, Silva ACRe, Richter MF, SaffiJ (2008). Antioxidant and antimutagenic properties of the monoterpene indole alkaloid psychollatine and the crude foliar extract of Psychotria umbellata Vell. Toxicol in Vitro. 22(3):559-566.

Fratianni F, Tucci M, Palma MD, Pepe R, Nazzaro F (2007). Polyphenolic composition in different parts of some cultivars of globe artichoke (Cynara cardunculus L. var. scolymus (L.) Fiori). Food Chem. 104(3):1282-1286.

Gil-Izquierdo A, Gil MI, Conesa MA, Ferreres F (2001). The effect of storage temperatures on vitamin $\mathrm{C}$ and phenolics content of artichoke (Cynara scolymus L.) heads. Innovat Food Sci Emerg Tech. 2(3):199-202.

Gebhardt R (1997). Antioxidative and Protective Properties of Extracts from Leaves of the Artichoke (Cynara scolymus L.) against Hydroperoxide-Induced Oxidative Stress in Cultured Rat Hepatocytes. Toxicol. Appl. Pharmacol. 144(2):279-286.

Gouveia SC, Castilho PC (2012). Phenolic composition and antioxidant capacity of cultivated artichoke, Madeira cardoon and artichoke-based dietary supplements. Food Res International. 48(2):712-724.

Guimarães AG, Oliveira GF, Melo MS, Cavalcanti SCH, Antoniolli AR, Bonjardim LR, Silva FA, Santos JP, Rocha RF, Moreira JC, Araújo AA, Gelain DP, Quintans-Júnior LJ (2010). Bioassay-guided Evaluation of Antioxidant and Antinociceptive Activities of Carvacrol. Basic Clin. Pharmacol. Toxicol. 107(6):949-957.

Gülçin I (2012). Antioxidant activity of food constituents: an overview. Arch. Toxicol. 86(3):345-91.

Halliwell B (1991). Reactive oxygen species in living systems: Source, biochemistry, and role in human disease. Am. J. Med. 91(3):S14S22.

Hammouda FM, Seif El-Nesr MM, Ismail SI, Shahat AA (1991). HPLC evaluation of the active constituents in the newly introduced Romanian strain of Cynara scolymus cultivated in Egypt. Planta Med. 57(SUPPL. 2):A119-A120.

Häusler M, Ganzera M, Abel G, Popp M, Stuppner H (2002). Determination of caffeoylquinic acids and flavonoids inCynara scolymus L. by high performance liquid chromatography. Chromatographia. 56(7-8):407-411.

Jensen SJK (2003). Oxidative stress and free radicals. J. Mol Structure Theochem. 666-67:387-92.

Joy JF, Haber SL (2007). Clinical uses of artichoke leaf extract. Am. J. Health Syst. Pharm. 64(18):1904-1909.

Kraft K (1997). Artichoke leaf extract - Recent findings reflecting effects on lipid metabolism, liver and gastrointestinal tracts. Phytomedicine. 4(4):369-378.

Kryston TB, Georgiev AB, Pissis P, Georgakilas AG (2011). Role of oxidative stress and DNA damage in human carcinogenesis. Mutat Res. 711(1-2):193-201.

Kucukgergin C, Aydın AF, Özdemirler-Erata G, Mehmetçik G, KoçakToker N, Uysal M (2010). Effect of Artichoke Leaf Extract on Hepatic and Cardiac Oxidative Stress in Rats Fed on High Cholesterol Diet. Biol. Trace Elem. Res. 135(1-3):264-274.

Kumar U, Mishra M, Prakash V (2012). Assessment of antioxidant enzymes and free radical scavenging activity of selected medicinal plants. Free Radic and Antiox. 2(3):58-63.

Lattanzio V, Kroon PA, Linsalata V, Cardinali A (2009). Globe artichoke: A functional food and source of nutraceutical ingredients. $J$ of Functional Foods. 1(2):131-144.

Letelier ME, Molina-Berrios A, Cortes-Troncoso J, Jara-Sandoval J, Holst M, Palma K, Montoya M, Miranda D, González-Lira V (2008). DPPH and oxygen free radicals as pro-oxidant of biomolecules. Toxicol. In Vitro. 22(2):279-286.

Li X, Mai W, Wang L, Han W (2013). A hydroxyl-scavenging assay based on DNA damage in vitro. Anal. Biochem. 438(1):29-31.

Liochev SI (2013). Reactive oxygen species and the free radical theory of aging. Free Radic. Biol. Med. 60:1-4.

Llorach R, Espín JC, Tomás-Barberán FA, Ferreres F (2002). Artichoke (Cynara scolymus L.) Byproducts as a Potential Source of HealthPromoting Antioxidant Phenolics. J. Agric. Food Chem. 50(12):3458- 
64.

Locatelli M, Gindro R, Travaglia F, Coïsson J-D, Rinaldi M, Arlorio M (2009). Study of the DPPH-scavenging activity: Development of a free software for the correct interpretation of data. Food Chem. 114(3):889-897.

Lombardo S, Pandino G, Mauromicale G, Knödler M, Carle R, Schieber A (2010). Influence of genotype, harvest time and plant part on polyphenolic composition of globe artichoke [Cynara cardunculus $\mathrm{L}$. var. scolymus (L.) Fiori]. Food Chem. 119(3):1175-1181.

Lutz M, Henríquez C, Escobar M (2011). Chemical composition and antioxidant properties of mature and baby artichokes (Cynara scolymus L.), raw and cooked. J. Food Comp. Anal. 24(1):49-54.

Miccadei S, Di Venere D, Cardinali A, Romano F, Durazzo A, Foddai MS, Fraioli R, Mobarhan S, Maiani G (2008). Antioxidative and Apoptotic Properties of Polyphenolic Extracts from Edible Part of Artichoke (Cynara scolymus L.) on Cultured Rat Hepatocytes and on Human Hepatoma Cells. Nutr. Cancer. 60(2):276-283.

Mishra K, Ojha H, Chaudhury NK (2012). Estimation of antiradical properties of antioxidants using DPPH assay: A critical review and results. Food Chem. 130(4):1036-1043.

Moravia WG, Lange LC, Amaral MCS (2011). Avaliação de processo oxidativo avançado pelo reagente de Fenton em condições otimizadas no tratamento de lixiviado de aterro sanitário com ênfase em parâmetros coletivos e caracterização do lodo gerado. Quim Nova. 34:1370-1377.

Mulinacci N, Prucher D, Peruzzi M, Romani A, Pinelli P, Giaccherini C Vincieri FF (2004). Commercial and laboratory extracts from artichoke leaves: estimation of caffeoyl esters and flavonoidic compounds content. J. Pharm. Biomed. Anal. 34(2):349-357.

Muntané J, Rosa AJ, Marín LM, Padillo FJ (2013). Nitric oxide and cell death in liver cancer cells. Mitochondrion. 13(3):257-262.

Nassar MI, Mohamed TK, Elshamy AI, El-Toumy SA, Lateef AMA Farrag A-RH (2013). Chemical constituents and anti-ulcerogenic potential of the scales of Cynara scolymus (artichoke) heads. J. Sci. Food Agric. 93(10):2494-2501.

Niki E (2009). Lipid peroxidation: Physiological levels and dual biological effects. Free Radic. Biol. Med. 47(5):469-84.

Niki E (2010). Assessment of Antioxidant Capacity in vitro and in vivo. Free Radic. Biol. Med. 49(4):503-515.

Oyedemi SO, Oyedemi BO, Arowosegbe S, Afolayan AJ (2012). Phytochemicals Analysis and Medicinal Potentials of Hydroalcoholic Extract from Curtisia dentata (Burm.f) C.A. Sm Stem Bark. Int. J. Mol. Sci. 13(5):6189-6203.

Palermo M, Colla G, Barbieri G, Fogliano V (2013). Polyphenol Metabolite Profile of Artichoke Is Modulated by Agronomical Practices and Cooking Method. J. Agric. Food Chem. 61(33):7960-8.

Pandino G, Lombardo S, Mauromicale G, Williamson G (2011). Profile of polyphenols and phenolic acids in bracts and receptacles of globe artichoke (Cynara cardunculus var. scolymus) germplasm. J. Food Compos Anal. 24(2):148-153.

Qiang Z, Lee S-O, Ye Z, Wu X, Hendrich S (2012). Artichoke Extract Lowered Plasma Cholesterol and Increased Fecal Bile Acids in Golden Syrian Hamsters. Phytother. Res. 26(7):1048-1052.
Ranilla LG, Kwon Y-I, Apostolidis E, Shetty K (2010). Phenolic compounds, antioxidant activity and in vitro inhibitory potential against key enzymes relevant for hyperglycemia and hypertension of commonly used medicinal plants, herbs and spices in Latin America. Bioresour. Technol. 101(12):4676-4689.

Re R, Pellegrini N, Proteggente A, Pannala A, Yang M, Rice-Evans C (1999). Antioxidant activity applying an improved ABTS radical cation decolorization assay. Free Radic. Biol. Med. 26(9-10):1231-1237.

Rosa SD, Bristot MLU, Topanotti MFL, Tomasi CD, Felisberto F, Vuolo FS, Petronilho F, Pizzol FD, Ritter C (2011). Efeito da transfusão de concentrado de hemácias sobre parâmetros de inflamação e estresse oxidativo em pacientes criticamente enfermos. Rev bras ter intensiva. 23:30-5.

Ruch RJ, Cheng S-j, Klaunig JE (1989). Prevention of cytotoxicity and inhibition of intercellular communication by antioxidant catechins isolated from Chinese green tea. Carcinogenesis. 10(6):1003-1008.

Saad H, Bouhtoury FC, Pizzi A, Rode K, Charrier B, Ayed N (2012). Characterization of pomegranate peels tannin extractives. Ind Crop Prod. 40:239-246.

Sailaja Rao P, Kalva S, Yerramilli A, Mamidi S (2011). Free Radicals and Tissue Damage: Role of Antioxidants. Free Radic and Antiox. 1(4):2-7.

Seneviratne KN, Kotuwegedara RT (2009). Antioxidant Activities of the Phenolic Extracts of Seed Oils and Seed Hulls of Five Plant Species. Food Sci. Technol. Intern. 15(5):419-425.

Silva CG, Herdeiro RS, Mathias CJ, Panek AD, Silveira CS, Rodrigues VP, Rennó MN, Falcão DQ, Cerqueira DM, Minto AB, Nogueira FL, Quaresma CH, Silva JF, Menezes FS, Eleutherio EC (2005). Evaluation of antioxidant activity of Brazilian plants. Pharmacol. Res. 52(3):229-233.

Singleton VL, Orthofer R, Lamuela-Raventós RM (1999). Analysis of total phenols and other oxidation substrates and antioxidants by means of folin-ciocalteu reagent. In: Lester $P$, editor. Meth Enzymology: Academic Press; p. 152-178.

Toma CC, Pribac GC, Neag TA, Câmpean RF, Olah NK (2013). Correlation between the polyphenol content and antioxidant effect of Cynara Scolymus L. mother tincture. Studia Univ. VG, SSV. 23(1):95100.

Wang M, Simon JE, Aviles IF, He K, Zheng Q-Y, Tadmor Y (2003). Analysis of Antioxidative Phenolic Compounds in Artichoke (Cynara scolymus L.). J. Agric. Food Chem. 51(3):601-608.

Zan MA, Ferraz ABF, Richter MF, Picada JN, de Andrade HHR, Lehmann M, Dihl RR, Nunes E, Semedo J, Da Silva J (2013). In Vivo Genotoxicity Evaluation of an Artichoke (Cynara scolymus L.) Aqueous Extract. J. Food Sci. 78(2):T367-T371.

Zhu X, Zhang H, Lo R (2004). Phenolic Compounds from the Leaf Extract of Artichoke (Cynara scolymus L.) and Their Antimicrobial Activities. J. Agric. Food Chem. 52(24):7272-7278. 